\title{
EDITORIAL
}

\section{Reproductive Immunology Issue One: Cellular and Molecular Biology}

\author{
Guest Editor B Anne Croy
}

Cellular \& Molecular Immunology (2014) 11, 405-406; doi:10.1038/cmi.2014.64; published online 28 July 2014

It is estimated that immune system evolution commenced more than 600 million years ago (Mya) when ancestral forms of MHC and CD45 appeared establishing innate immunity. ${ }^{1}$ By 500 Mya, RAG gene evolution had occurred, founding adaptive immunity. ${ }^{2}$ The first mammals appeared much later (220 Mya) and reproduced by laying of eggs. Placental mammals with internal gestations and live born offspring have existed for only 100 Mya, with humans and mice being relatively recent mammalian evolutions. This historical record indicates that the evolution of viviparity must have involved processes that were immunologically unrecognized, immunologically accepted or occurred at accelerated rates that could not be immunologically regulated.

Placental evolution occurred repeatedly and is not regarded as incremental genetic changes but as catastrophically abrupt changes. Current research suggests acquisition of ancient retroviruses that drove cell fusion was critical for evolution of placental mammals. ${ }^{3,4}$ Histologically, placenta has the most diverse structure between species of any tissue. It is not yet known in detail whether immunological specializations at the maternal-fetal interface also vary widely between species. It is quite clear that innate immune cell populations have been specially adapted to this location in all species studied to date.

Reproductive Immunology became a research focus about 60 years ago as concepts regarding transplantation antigens and transplant rejection developed. A pioneering 1953 paper that heavily influenced development of this subspecialty was 'Some immunological and endocrinological problems raised by the evolution of viviparity in vertebrates. Symp. Soc. Exp. Biol. 7: 320-338' by Sir Peter Medawar ${ }^{5}$ who received the 1960 Nobel Prize in Medicine for developing concepts of immunological tolerance.

Antigens are not the only key regulators of immune cell biology in the reproductive tract; endocrine influences are critical. Further, reproductive immunology addresses not only pregnancy, but the reproductive tracts of males and non-gravid females. The many organs that comprise each of the male and

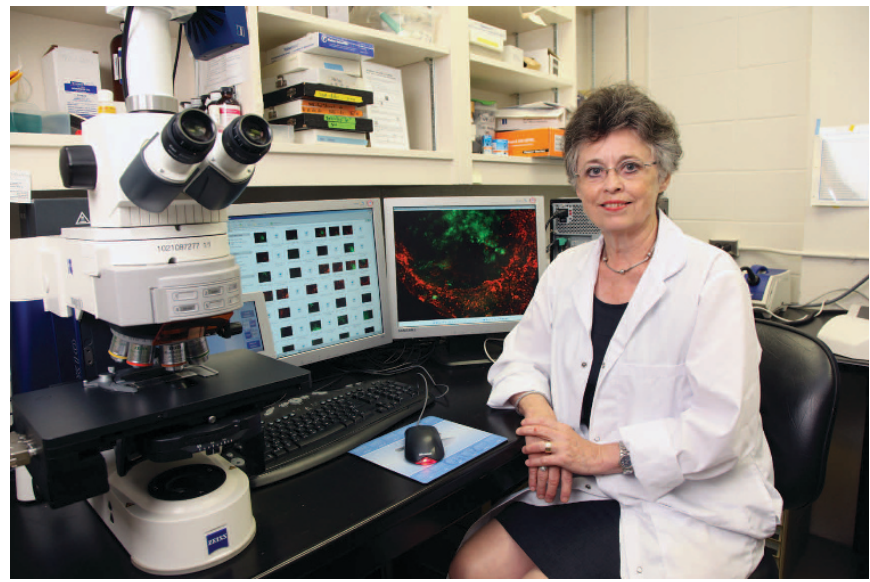

female reproductive systems are components of the mucosal immune system. Each is a specialized environment that makes unique contributions to the success of procreation and can experience immunologically based disease. These diseases have clinical importance not only for humans, ${ }^{6,7}$ but also in livestock production for food and in global protection of wild and captive or domesticated contemporary mammalian species. ${ }^{8,9}$

Contributors to this special issue of Cellular and Molecular Immunology were invited to highlight specific areas of Reproductive Immununology as a review, opinion or primary paper to showcase the breadth and importance of topics under intense investigation or of newer emerging importance. The triad of individuals involved in mammalian reproductive processes (mother, father, offspring), the dynamic, rapidly changing aspects of the maternal-fetal interface during development, the unique properties of reproductive tract immune cells and the lack of specimen availability during mid to late pregnancy in humans and wildlife, due to the desire of healthy offspring make reproductive immunology a challenging subject. Its importance, however, to every current, past and future 
mammal, cannot be overstated. Rather than addressing the mammalian conceptus as an allograft, parasite or transplant to be tolerated, appreciation of the unique immunological features of mammalian reproduction will be the approach most likely to advance translation of research in this field.

This special issue begins with a comprehensive review by Nguyen et al. ${ }^{10}$ of the immune systems of non-pregnant female and male reproductive tracts and the impact of endocrine influences. The unique compartmentalization of the reproductive tract from systemic immunity is emphasized as is its susceptibility to HIV-1 infection through sexual activity. Zhao and colleagues ${ }^{11}$ then address the defense system of the testes and the unique immune privilege it displays at the onset of puberty and male gametogenesis. The topic then moves to pregnancy. Matson and Caron ${ }^{12}$ discuss endocrine control of uterine immune cells during pregnancy, using adrenomedullin as an example hormone that participates in leukocyte localization and function at the maternal-fetal interface. Du and her colleagues review their comprehensive work and that of others on chemokines and chemokine receptor expression in early human implantation sites. ${ }^{13}$ Influences on leukocyte recruitment as well as on trophoblast invasion are discussed in normal as well as in pathological pregnancies. Lima and her colleagues ${ }^{14}$ then report on the roles of the LY49 receptor gene family during mouse pregnancy, focusing on subsets of uterine natural killer (NK) cells. These authors found selective alterations of NK cell functions in pan LY49 gene knockdown mice. This paper is followed by Rajagopalan's ${ }^{15}$ review of antigen expression by trophoblast (placental) cells and the responses recognition of these antigens induce in innate immune cells. A special state of secretory senescence is described in human uterine NK cells. This topic has the potential to reshape understanding of the unusual terminal differentiation of uterine immune cells that cease division but are not cleared as apoptotic cells. The contribution by Leno-Durán and her colleagues ${ }^{16}$ concludes the series of paper on innate immune responses during early pregnancy with a review on the interactions between dendritic cells and NK cells in decidua, a pregnancyinduced tissue of transiently transformed endometrial fibroblasts induced in species with hemochorial placentation.

In the next issue of the journal (Vol. 11, No. 6, November 2014), the theme of Reproductive Immunology will be continued. The November papers will discuss adaptive immunity, additional forms of leukocyte regulation and exchange at the maternal-fetal interface, infection and immune associations with labor. The potential for application of new diagnostic approaches in assessment of reproductive health will also be addressed. Together, the series of papers in this pair of special issues provides readers with a broad perspective of current research in reproductive immunology and the gaps in knowledge that invite the curious student or scientist. The immune system has always been of importance to placental mammals who have developed unique collaborative partnerships with it millions of years ago. In our contemporary framework, immune system promotion (immunotrophism) of reproductive success and immune system-induced complications and failures of reproduction provide key translational opportunities for health improvement in humans and other mammals.

Kingston, Ontario, Canada, 20 June 2014

1 Kasahara M, Suzuki T, Pasquier LD. On the origins of the adaptive immune system: novel insights from invertebrates and cold-blooded vertebrates. Trends Immunol 2004; 25: 105-111.

2 Flajnik MF, Kasahara M. Origin and evolution of the adaptive immune system: genetic events and selective pressures. Nat Rev Genet 2010; 11: 47-59.

3 Lee A, Nolan A, Watson J, Tristem M. Identification of an ancient endogenous retrovirus, predating the divergence of the placental mammals. Philos Trans R Soc Lond B Biol Sci 2013; 368: 20120503.

4 Dupressoir A, Vernochet C, Bawa O, Harper F, Pierron G, Opolon P et al. Syncytin-A knockout mice demonstrate the critical role in placentation of a fusogenic, endogenous retrovirus-derived, envelope gene. Proc Natl Acad Sci USA 2009; 106: 12127-12132.

5 Medawar PB. Some immunological and endocrinological problems raised by the evolution of viviparity in vertebrates. Symp Soc Exp Biol 1953; 7: 320-338.

6 Silva CA, Cocuzza M, Borba EF, Bonfa E. Cutting-edge issues in autoimmune orchitis. Clin Rev Allergy Immunol 2012; 42: 256-263.

7 Cheng MH, Nelson LM. Mechanisms and models of immune tolerance breakdown in the ovary. Semin Reprod Med 2011; 29: 308-316.

8 Sheldon IM, Cronin JG, Healey GD, Gabler C, Heuwieser W, Streyl D et al. Innate immunity and inflammation of the bovine female reproductive tract in health and disease. Reproduction 2014; in press.

9 Miller LA, Fagerstone KA, Eckery DC. Twenty years of immunocontraceptive research: Iessons learned. J Zoo Wildl Med 2013; 44(4 Suppl): S84-S96.

10 Nguyen PV, Kafka JK, Ferreira VH, Roth K, Kaushic C. Innate and adaptive immune responses in male and female reproductive tract in homeostasis and following HIV infection. Cell Mol Immunol 2014; 11: 410-427.

11 Zhao S, Zhu W, Xue S, Han D. Testicular defense systems: immune privilege and innate immunity. Cell Mol Immunol 2014; 11: 428437.

12 Matson BC, Caron KM. Mini Review: Adrnomedullin and endocrine control of immune cells during pregnancy. Cell Mol Immunol 2014; 11: 456-459.

13 Du MR, Wang SC, Li DJ. The integrative roles of chemokines at teh maternal-fetal interface in early pregnancy. Cell Mol Immunol 2014; 11: 438-448.

14 Lima PD, Tu MM, Rahim MM, Peng AR, Croy BA, Makrigiannis AP. LY49 receptors activate angiogenic mouse $\mathrm{DBA}^{+}$uterine natural killer cells. Cell Mol Immunol 2014; 11: 467-476.

15 Rajagopalan S. HLA-G mediated NK cell senescence promotes vascular remodeling: implications for reproduction. Cell $\mathrm{Mol}$ Immunol 2014; 11: 460-466.

16 Leno-Durán E, Munoz-Fernández R, Olivares EG, Tirado-González I. Natural killer cell and dendritic cell liasons in human gestation. Cell Mol Immunol 2014; 11: 449-455. 